\title{
FEKTIVITAS KOMUNIKASI DAKWAH: KECERDASAN KOMUNIKASI DAN RETORIKA DAKWAH
}

\section{Suharto}

Dosen Tetap Jurusan Komunikasi dan Penyiaran Islam FUAD IAIN Palu

\section{Abstract:}

The effectiveness of communication in doing da'wah is demanded for the development of da'wah in this era of global competition. Therefore, the presence of various models of communication today makes communication both as secondary and primary tool. Moslem preachers can build a design of da'wah communication based on technology to make it effective. In improving the effectiveness of da'wah communication, intellectual capability and da'wah rethoric are required including the use of communication technology. Implicitly, communication technology has become a main prerequisite for Moslem preachers to modernize da'wah rethoric in preaching. However, it is communication capabilities which make da'wah rethoric being carried out well, and in turn, da'wah rethoric will have a high value in the community.

$$
\begin{aligned}
& \text { وقد احتاجت الدعوة إلى حوار تفاعلي فى زمان تنافس إجالي. ولهذا كان وجود أنواع طرق الإتصال }
\end{aligned}
$$

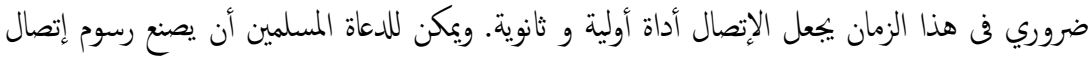

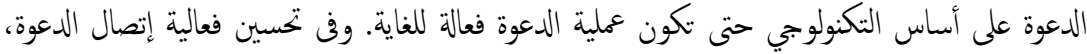

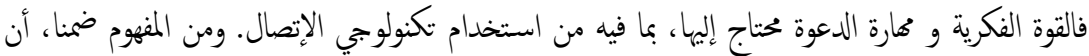

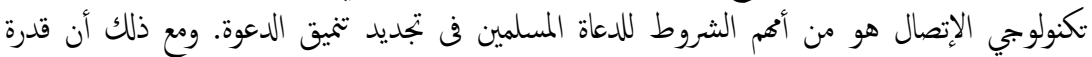

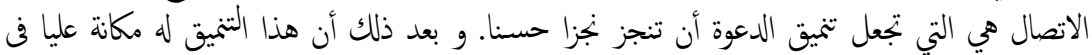

Kata Kunci: efektivitas, kecerdasan komunikasi, retorika dakwah.

\section{Pendahuluan}

Perkembangan komunikasi menjadi sedemikian pesat, tumbuh berkembang mengiringi laju gerak langkah manusia. Bayang-bayang kemajuan komunikasi berikut terkonologinya, sungguh-sungguh terasa dan tampak mewarnai sehari-hari kita. Perkembangannya bukan hanya terlihat dari aspek komunikasi sebagai sebuah disiplin ilmu pengetahuan, seperti yang terlihat dan menghiasi berbagai perguruan tinggi secara 
global yang menjadikan ilmu komunikasi sebagai bagian yang berdiri sendiri dalam bentuk jurusan, fakultas atau departemen, bahkan telah banyak berdiri sekolah tinggi, institut atau semacamnya yang khusus menyiapkan program ilmu komunikasi semata.

Komunikasi bukan sekedar menjadi milik dan alat pemerintah saja, untuk menjalankan aktivitas pelayanan dan pembangunan. Komunikasi bukan hanya tugas sang diplomat yang harus cakap dan lihai berkomunikasi dalam menjalin dan membangun diplomasidiplomasi. Nun, di luar sana, di sekliling kita dan bahkan dipinggiranpinggiran hingga ke pelosok-pelosok kampung sekalipun, komunikasi dan teknologi informasinya telah menjadi varian utama masyarakat dalam menjalani kesehariannya dan mengikuti perkembangan dan trend-trend komunikasi sebagaimana layaknya masyarakat urban yang hidupnya di kota-kota besar dan sekitarnya.

Teknologi informasi telah memberikan stimulus bagi warga masyarakat untuk turut larut dalam dinamisnya kehidupan modern. Bahkan kehadiran berbagai model komunikasi dewasa ini menjadikan komunikasi sebagai alat sekunder yang hanya sekedar eforia zaman modernis dan menyahuti hasrat globalisasi, namun keingintahuan dan melek informasi ter-up date merupakan juga sebuah kebutuhan yang ingin didapat dan dirasakan seketika itu pula. Masyarakat luas tidak lagi harus menunggu waktu lama jika ingin mengetahui desas desus politik, problematika perkotaan dan informasi-informasi hot lainnya. Masyarakat dengan mudah dapat membangun interaksi-interaksi yang merupakan reaksi menyikapi atau feedback atas aksi-aksi media-media komunikasi yang menyampaikan pesan-pesan informasi menarik dan variatif, pesan yang menghibur dan mendidik serta bagian-bagian pesan-pesan lainnya yang sekejap dapat diterima dan dalam waktu bersamaan bisa melakukan umpan balik.

Heath dan Bryan dalam Bambang S Ma'arif (2010) mendefinisikan komunikasi sebagai suatu proses atau seperangkat tindakan di mana masyarakat bersama-sama dalam simbol-simbol yang mereka ciptakan melalu interaksi. Dalam pandangan ini, dapat 
diinternalisasikan bahwa komunikasi memiliki seperangkat sistem yang berfungsi untuk menghantar pesan kepada khalayak. Bahwa seperangkat sistem itulah yang bersenyawa dengan teknlogi-teknologi yang menghasilkan berbagai macam model dan bentuk komunikasi. sehingga, memudahkan para pelaku komunikasi mengefektifkan dan mengefisiensikan proses komunikasi. ${ }^{1}$

Para komunikator-komunikator pembangunan, komunikator dakwah hingga para pekerja politik dan pebisnis sekalipun tidak lagi dipusingkan untuk bagaimana agar pesan-pesan yang ingin disampaikan kepada publik atau masyarakat bisa sampai lebih cepat atau tepat waktu. Sebab, modernisasi teknologi komunikasi dan informasi menepis ketakutan-ketakutan itu dan memberikan beragam solusi teknologi tepat guna yang sangat membantu aktivitas-aktivitas mereka. Para da $i$ atau komunikator dakwah misalnya, jika ingin menyampaikan pesan-pesan dakwah kepada mad'u (khalayak) sudah banyak metode yang siap dipilih dan pergunakan sesuai dengan situasi dan kondisi komunikan yang ingin dijamah.

Bentuk komunikasinya pun sudah sangat variatif, para daßi juga sudah dapat membuat bangun rancang komunikasi dakwah yang berbasis teknologi. Implisitnya teknologi komunikasi tersebut telah menjadi prasyarat utama bagi da $\not{i}$ untuk memodernisasi retorika dakwah yang akan menjadi sajian mereka dalam berdakwah. Bagaimanakah kecerdasan komunikasi dan retorika dakwah yang menunjang efektifitas komunikasi dakwah? Hal inilah yang akan penulis bahas dalam uraian tulisan ini.

\section{Pembahasan}

\section{Retorika Dakwah}

Retorika adalah bagian dari seni berkomunikasi, menurut Hendrikus (dalam Bambang S. Ma'arif, 2010) retorika berarti seni untuk

${ }^{1}$ Bambang S. Ma'arif, Komunikasi Dakwah; Paradigma untuk Aksi, (Bandung: Simbiosa Rekatama Media, Cetakan Pertama, 2010), h. 115 
berbicara baik, yang dicapai berdasarkan bakat alam dan keterampilan teknik $^{2}$. Retorika harus mencari kebenaran, bukannya mempermainkan kata-kata kosong. Dalam menyampaikan materi-materi dakwah, da'i dituntut agar dapat menyampaikannya dengan cara berkomunikasi dengan baik dan berseni. Retorika merupakan sebuah seni berpidato untuk menyajikan pesan-pesan yang dapat membujuk, merangsang dan menyakinkan pendengar (pemirsa atau komunikan) dengan bertutur kata yang retorik dan bermakna serta logis, tujuannya tak lain adalah agar audiens atau khalayak pemirsa atau pendengar bisa meyakini dan menerima kebenaran informasi yang didapatnya secara logika dan rasional. Ini sejalan dengan pendapat Rybecki (1991) yang mengatakan bahwa fungsi retorika adalah untuk menjadikan kebenaran tampak melalui penerapan logika. ${ }^{3}$

Aristoteles mengatakan bahwa ada 2 (dua) bidang bukti (proofs) atau imbauan (appeals) yang mempengaruhi komunikasi secara persuasi, yaitu inartistic dan artistic. Bukti-bukti in-artistic adalah semua aspek dari situasi dan kualitas pembicaraan yang tidak secara langsung dikontrol oleh pembicaranya, sedang artistic merupakan bukti (kualitas) yang langsung dikuasai pembicara. ${ }^{4}$

Retorika merupakan bagian dari komunikasi publik menurut Griffin dan MicKeon, ${ }^{5}$ yang berfungsi untuk membahas persoalanpersoalan yang masih mungkin, mencoba menunjukkan kebenaran yang ditemukan dan mengupas perkara-perkara yang berguna secara praktis. Rybecki lebih lanjut mengatakan teori retorika adalah suatu perkembangan terhadap observasi dari praktik public speaking dalam kebudayaan klasik, undang-undang (Canon) menjadi alat analisis

\footnotetext{
${ }^{2}$ Ibid.

${ }^{3}$ Ibid.

${ }^{4}$ Ibid., h. 117

${ }^{5}$ Ibid.
} 


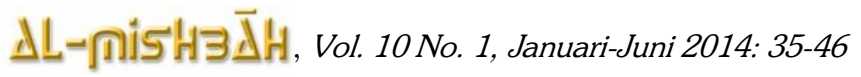

berbicara paling layak. Jadi, kita lebih memusatkan kepada retor, audiens, dan pesan. ${ }^{6}$

O'Shaugnessy (Dalam Bambang) seorang pakar periklanan mengatakan:

"Di dalam retorika, imbauan-imbauan emosional sama relevannya dengan imbauan rasional, dan Aristoteles memandang retorika sebagai panduan emosi dan rasional. Dia memberikan perhatian kepada keduanya (imbauan emosi dan rasio) karena banyak hal yang bisa dilaksanakan, (yang pada intinya) bahwa retorika sekitar opini (doxa) daripada pengetahuan tertentu (epistema)". ${ }^{7}$

Kemudian Dakwah sendiri diambil dari satu pengertian umum yang secara bahasa diambil dari kata دع بدعو- دعوة yang berarti "mengajak", "memanggil", "mengundang", "mendorong". Toha Yahya Umar mengatakan, dakwah adalah; "Mengajak manusia dengan cara bijaksana kepada jalan yang benar sesuai perintah Tuhan, untuk kemaslahatan dan kebahagian mereka di dunia dan di akhiraf'. 8 Sedangkan Shekh Ali Mahfuz mengatakan, dakwah adalah "Mendorong manusia atas kebaikan dan mencegah dari kemungkaran guna mendapatkan kebahagiaan hidup di dunia dan di akhirat". "Dari kondisi) Positif kekondisi yang lebih positif'. ${ }^{9}$

Retorika dakwah tidak lepas dari asumsi-asumsi dan teori retorika pada umumnya, yakni suatu usaha seorang retor dakwah atau da'i untuk melakukan komunikasi dakwah dengan mengacu kepada fungsi-fungsi dari retorika itu sendiri. Komunikator dakwah harus mampu melakukan improvisasi metode dakwah yang berkualitas dengan penyampaian yang menarik dan mengesankan dengan tujuan agar pendengar atau pemirsa dapat larut, mengerti, paham dan yakin akan fakta-fakta yang disampaikannya.

${ }^{6}$ Ibid., h. 121

${ }^{7}$ Ibid.

${ }^{8}$ Toha Yahya Umar, Ilmu Dakwah, (Cet. IV; Jakarta: Widjaya, 1985), h. 1

${ }^{9}$ Shekh Ali Mahfuz, Hidāyah Murshidin ilā Turuqi an-Nās wa AlkhaṬabah, (Beirut: Dār al-Ma'ārif, tth), h. 1 
Suharto, Efektivitas Komunikasi Dakwah....

Pendekatan persuasi dalam beretorika dalam medan dakwah adalah suatu yang urgen dan sangat berguna. Sebab persuasi dalam pengertian yang beragam sebagai bentuk komunikasi yang memiliki tujuan membujuk, merayu dan meyakinkan orang, baik yang dilakukan dengan simbol-simbol maupun dalam seni berbicara yang bisa memotivasi dan menaruh perhatian dan harapan terhadap komunikasi yang dilangsungkan melalui persuasi.

Komunikasi persuasi lebih menekankan pada daya tarik fisik dan kepribadian-sebagaimana dipersepsikan oleh audiens menjadi komponen-komponen dari transaksi persuasi. Implikasinya adalah bahwa seorang yang bermaksud memersuasi audiens lebih efektif dengan memberikan perhatian pada daya tariknya (his or her own atractiveness). ${ }^{10}$

\section{Kecerdasan Komunikasi}

Keberhasilan komunikator dakwah dalam menyampaikan komunikasi kepada audiens atau khalayak tidak terlepas dari kepiawaian sang retor dakwah tersebut mempergunakan kesempatannya untuk mengeksplorasi skill individu pada dirinya. Seorang da'i harus memiliki kemampuan dan kepribadian berkomunikasi secara kreatif. Bahwa komunikator dakwah tidak datang tiba-tiba atau instan, melainkan ia lahir dari proses panjang hingga membentuk dirinya sebagai pribadi yang cerdas dan berkepribadian menarik. Kreatifitas menjadi salah satu kunci kesuksesan seorang retorika dakwah akan sangat berkaitan dengan model dan bentuk komunikasi yang dipergunakan dalam berdakwah. Termasuk komunikasi persuasi sangat penting untuk melakukan kreatifitas dalam merancang penyampaian komunikasi saat berkhotbah, ceramah, mimbar bebas dan bentuk-bentuk komunikasi dakwah lainnya.

Setidaknya ada tiga langkah yang harus dipersiapkan oleh komunikator dakwah sebelum menjalankan aktivitas dakwah atau

${ }^{10}$ Bambang, Komunikasi..., h. 127-128 
pidato. Setelah memahami tipe pidato, format penyajian, unsur-unsur fisik yang perlu diperhatikan, maka menurut Idi Subandi Ibrahim langkah berikutnya adalah persiapan pidato di depan umum atau dalam situasi komunikasi yang mungkin akan dihadiri banyak orang yang ingin mendengar pidato anda, Pertama Persiapkan isi materi yang akan Anda sampaikan. Kedua Persiapkan suara Anda, dan Ketiga Persiapkan penampilan anda ${ }^{11}$.

Komunikator dakwah yang cerdas dalam artian bahwa ia mampu memkombinasikan kreatifitas dakwah yang dinamis dan berkarakter dengan kepribadiannya yang menarik dan terpercaya. sehingga, ia dituntut untuk mampu mengekspresikan dirinya dalam berdakwah dengan tidak kaku, tidak monoton dan tidak bombastis. Tetapi sebaliknya da'i cerdas adalah seorang pribadi yang senantiasa melakukan inovasi-inovasi gagasan dan memiliki cakrawala yang luas yang dipadu dengan kreatifitas gerakan tubuh dan penampilan yang menawan sehingga benar-benar audiens mampu terkesima dan memiliki keyakinan mendalam bahwa sang da'i memiliki kredibilitas dan kapasitas yang mumpuni dalam menyampaikan kebenaran-kebenaran kelak dalam menyampaikan orasi-orasi dakwahnya.

Untuk itu kecerdasan komunikasi dalam konteks komunikasi dakwah adalah bagaimana seorang komunikator dakwah mampu menjadi pembicara terbaik dengan memiliki kemampuan-kemampuan dan skill individu sebagai berikut:

1. Komunikator dakwah harus mampu melahirkan inovasi-inovasi materi dakwah setiap saat dan menyampaikan fakta-fakta kebenaran dari sudut pandang baru dan berbeda.

2. Komunikator dakwah harus berwawasan luas, memiliki pengetahuan multi disiplin. Bahwa di dalam menyampaikan kebenaran-kebenaran dalam bentuk khotbah, pidato dan ceramah agama dibutuhkan pengetahuan multi untuk

${ }^{11}$ Idi Subandi Ibrahim, Kecerdasan Komunikasi: Seni Berkomunikasi Kepada Publik, (Bandung: Simbiosa Rekatama Media, Bandung, 2009), h. 100-101 
Suharto, Efektivitas Komunikasi Dakwah....

mengeksplor ayat-ayat Tuhan yang disesuaikan dengan kondisi dan situasi jama'ah.

3. Retorika dakwah harus terlihat antusias, energik dan memperlihatkan kepada khalayak atau jama'ah bahwa sang da'i mampu menyelami kehidupannya dan peduli terhadap kondisi yang dihadapinya.

4. Retorika dakwah senantiasa menghindari memuji atau membicarakan diri sendiri. Tetapi selayaknya komunikator dakwah melakukan kreasi-kreasi penampilan, model komunikasi persuasi yang heorik, kharismatik dan efektif sehingga jamaah terkesima dengan penampilannya.

5. Da'i harus memiliki selera humor untuk mengimbangi kejenuhan, mengantipasi agar pendengar tidak bosan.

6. Da'i harus memiliki ciri khas atau karakter dalam berkomunikasi baik gaya, intonasi, dan penampilan berpakaian.

7. Komunikator dakwah harus menguasi teknologi komunikasi dan informasi untuk memodifikasi bentuk-bentuk komunikasi dakwah yang bisa bersinergi dengan perkembangan modern.

Kecerdasan Komunikasi dan retorika dakwah akan lebih mendukung dan semakin efektif jika penerapan nilai dan etika dalam berdakwah menjadi bahagian dari kemampuan kecerdasan komunikasi dan retorika dakwah. Nilai tersebut adalah;

a. àdam al-ikrah fi al-din (menghargai kebebasan, menghormati hak asasi masing-masing individu dan masyarakat)

b. àdamul kharaj (menghindari kesulitan, kesempitan, dan kepicikan)

c. däf al-ḍarar wa al-mufașid (menghindari kemadharatan dan kerusakan)

d. al-tadarruj (bertahap, gradual dan mengikuti proses)

e. al-tawi wa al-taghyi (melakukan evaluasi secara sinergis dan bertahap)

f. al-uswah wal-qudwah (berilah contoh dan suri tauladan yang baik)

g. al-tatbiqi wa al amali (perbuatlah dan aplikasikan apa yang telah diucapkan) 


\section{$\Delta$ L-مis H3 $3 \bar{\Delta}$ H, Vol. 10 No. 1, Januari-Juni 2014: 35-46}

h. al-takrir wa al murajäah (teruslah melakukan pengulangan hingga audiens memahami)

i. al-taqyim (evaluasilah kembali apa yang sudah disampaikan)

j. al-hiwār (berkomunikasi dengan rasa kebersamaan dan kesetaraan)

k. al-qișah (berceritalah dengan mereka agar terjalin kehangatan hubungan)

1. al-dārs (berilah mereka pengajaran yang dapat membangkitkan kemampuan akal mereka). ${ }^{12}$

Sedangkan etika komunikasi dakwah, menurut Ali Aziz adalah;

a. al-yaqin lā yuza'l bi al-shākk (keyakinan tidak dapat dihilangkan dengan keraguan), ${ }^{13}$ bahwa apa yang disampaikan adalah kebenaran yang tak diragukan lagi.

b. al-darar yuza'l (bahaya itu harus dihilangkan), maksudnya menurut al-Ghazali, ${ }^{14}$ bahwa pendakwah dibolehkan berhenti berdakwah jika ada ancaman yang membahayakan jiwanya maupun keluarganya.

c. al-mashaqqah tajilib al-taisir (kesulitan dapat mendatangkan kemudahan), ${ }^{15}$ maksudnya orang muslim yang terpaksa mengakui kemusyrikan hanya dengan lisan, bukan hatinya, demi mempertahankan nyawanya dibolehkan oleh agama (seperti kasus sahabat 'Ammar bin Yasir). Setelah dirinya merasa aman, ia harus kembalig pada imannya.

d. al-ádah muhakkamah (adat istiadat dapat menjadi hukum) ${ }^{16}$ maksudnya pendakwah harus memperhatikan kearifan lokal saat melaksanakan dakwah pemberdayaan masyarakat.

e. al-khurüj min al-khiläf mustahāb (keluar dari perbedaan pendapat para ulama dianjurkan), ${ }^{17}$ maksudnya pendakwah tidak dibenarkan

12 Sulaiman, Minhaj al-Islami. (Jakarta: Serambi. 2002), h.10.

${ }^{13}$ Moh. Ali Aziz, Ilmu Dakwah, edisi Revisi, (Cet. II. Jakarta: Kencana. 2009), h. 167.

14 Ibid.

15 Ibid.

16 Ibid.

${ }^{17} \mathrm{Ibid}$. 
menyampaikan pesan dakwah yang dapat memperuncing perselisihan di masyarakat. ${ }^{18}$

Nilai dan etika ini harus menyatu pada perangai da'i, Asep Muhyidin juga menjelaskan tentang keharusan perangai da'i sesuai Alqur'ān dalam surah Annahal (16): $125 ;{ }^{19}$ bahwa perangai da'i harus menyerupai lebah. Watak lebah dari mulai mencari makanan di tempat yang bersih (pada bunga-bunga dengan mengambil sarinya), proses mendapatkan makanan itu tidak merusak bahkan membantu proses pembuahan yang bermanfaat bagi pepohonan, menghasilkan madu yang sangat banyak manfaatnya untuk pengobatan berbagai penyakit, tidak mengusik-ngusik mahluk lain tetapi ketika diusik maka ia akan mengejar siapapun yang mengusik hingga si pengusik mencebur ke dalam air. ${ }^{20}$

Dalam penjelasan lebih lanjut, ibrah mengandung makna bahwa da'i itu dituntut selektif dalam hidup kesehariannya seperti makanan yang halal, bersih dan bergizi; agar kehadirannya di mana saja selalu membawa kemanfaatan dan keberkahan bagi lingkungan sekitarnya; mampu memberi solusi berbagai persoalan yang ada di tengah-tengah masyarakatnya; berwibawa, kharismatik. Kompleksitas unsur kecerdasan komunikasi, retorika, profesional menerapkan nilai, etika dan kharisma seorang komunikator atau da'i-lah yang dapat merealisasikan komunikasi dakwah yang efektif.

\section{Penutup}

Akhirnya, secara philosofis dapat disimpulkan bahwa komunikasi dakwah merupakan senyawa proses yang terkandung dalam kecerdasan komunikasi dan retorika dakwah yang menghasilkan seorang

\section{${ }^{18}$ Ibid.}

${ }^{19}$ Kementerian Agama RI, Alqurān dan Terjemahnya, (Bandung: Fokus Media, 2010), h. 281

${ }^{20}$ Asep Muhyidin, Dakwah dalam Perspektif Alqurān, Studi Kritis atas Visi, Misi dan Wawasan, (Bandung: Pustaka Setia. 2002), h. 163-169. 


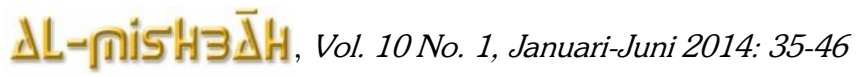

komunikator atau retor dakwah yang memiliki kemampuan yang bersumber dari skill individunya serta teknik-teknik berkomunikasi yang menyatu dalam merancang agenda-agenda dakwah sehingga menghasilkan agenda setting dakwah yang berkualitas dengan kemampuannya membangun karakter pribadi.

Komunikator dakwah lahir dari proses panjang hingga membentuk dirinya sebagai pribadi yang cerdas dan berkepribadian menarik. Kreatifitas menjadi salah satu kunci kesuksesan seorang retorika dakwah akan sangat berkaitan dengan model dan bentuk komunikasi yang dipergunakan dalam berdakwah. Termasuk komunikasi persuasi sangat penting untuk melakukan kreatifitas dalam merancang penyampaian komunikasi saat berkhotbah, ceramah, mimbar bebas dan bentuk-bentuk komunikasi dakwah lainnya. Setidaknya ada tiga langkah-langkah yang harus dipersiapkan oleh komunikator dakwah sebelum menjalankan aktivitas dakwah atau pidato. Setelah memahami tipe pidato, format penyajian, unsur-unsur fisik yang perlu diperhatikan, maka menurut Idi Subandi Ibrahim langkah berikutnya adalah persiapan pidato di depan umum atau dalam situasi komunikasi yang mungkin akan dihadiri banyak orang yang ingin mendengar pidato Anda, Pertama Persiapkan isi materi yang akan disampaikan. Kedua Persiapkan suara, dan Ketiga Persiapkan penampilan.

Dengan demikian maka hasil dari kecerdasan komunikasi itulah sehingga retorika dakwah dapat terlaksana dengan baik, dan retor dakwah akan memiliki kredibilitas tinggi dalam masyarakat. 
Suharto, Efektivitas Komunikasi Dakwah....

\section{Daftar Pustaka}

Aziz, Moh. Al, Ilmu Dakwah, edisi Revisi, Cet. II. Jakarta: Kencana. 2009.

Bambang S Ma'arif, Komunikasi Dakwah; Paradigma Untuk Aksi, Cet. I, Bandung: Simbiosa Rekatama Media, 2010

Idi Subandi Ibrahim, Kecerdasan Komunikasi: Seni Berkomunikasi Kepada Publik, Cet. II, Bandung: Simbiosa Rekatama Media, 2009.

Kementerian Agama RI, Alqurān dan Terjemahnya, Bandung: Fokus Media, 2010.

Mahfuz, Syekh Ali, Hidāyah Murshidin ilā Turuqi an-Nāṣ wa Alkhatabah, Beirut: Dār al-Ma'ārif, tth.

Muhyidin, Asep, Dakwah dalam Perspektif Alqurān, Studi Kritis atas Visi, Misi dan Wawasan, Bandung: Pustaka Setia. 2002.

Sulaiman, Minhaj al-Islami. Jakarta: Serambi. 2002

Umar, Toha Yahya, Ilmu Dakwah, Cet. IV; Jakarta: Widjaya, 1985. 